\title{
Opioid Modulation of Recurrent Excitation in the Hippocampal Dentate Gyrus
}

\author{
Gregory W. Terman, ${ }^{1,3}$ Carrie T. Drake, ${ }^{4}$ Michele L. Simmons, ${ }^{2}$ Teresa A. Milner, ${ }^{4}$ and Charles Chavkin ${ }^{2,3}$ \\ Departments of ${ }^{1}$ Anesthesiology and ${ }^{2}$ Pharmacology and ${ }^{3}$ the Graduate Program in Neurobiology and Behavior, \\ University of Washington School of Medicine, Seattle, Washington 98195-6540, and 4 Department of Neurology and \\ Neuroscience, Weill Medical College of Cornell University, New York, New York 10021
}

$\kappa$ opioid receptor activation inhibits granule cell-mediated excitatory neurotransmission in the hippocampal formation via a decrease in glutamate release from both perforant path and mossy fiber terminals. We now report a third, anatomically and pharmacologically distinct site of such $\kappa$ opioid inhibition within the hippocampus. Granule cell population responses to selective stimulation of an excitatory hilar pathway were decreased by the $\kappa_{1}$ opioid receptor agonist U69,593, an effect blocked by the $\kappa_{1}$ antagonist norbinaltorphimine. U69,593 also inhibited hilar path induced long-term potentiation (LTP) of granule cell responses. LTP in this pathway was also blocked by the NMDA receptor antagonist D-2-amino-5-phosphonovalerate, unlike granule cell mossy fiber LTP in CA3.

The $\kappa$ opioid peptide dynorphin is present in hilar mossy fiber collaterals. Ultrastructural analysis of these collaterals demonstrated dynorphin-containing vesicles in asymmetric synapses formed between axon terminals and granule cell dendrites, suggesting direct granule cell-granule cell connections. Evoked release of endogenous dynorphin within the hilus was effective in reducing hilar excitation of granule cells, although this release, in contrast to the release of dynorphin in the dentate molecular layer, was not dependent on L-type calcium channels.

No hilar path excitation was observed in the absence of bicuculline, suggesting a strong $\mathrm{GABA}_{A}$-mediated inhibition of this pathway. However, hilar path activity could be seen after LTP, with or without bicuculline. Thus, $\kappa$ opioids can inhibit granule cell recurrent excitation, likely via effects on excitatory mossy fiber collaterals. Such collaterals are thought to be important in mediating temporal lobe epilepsy.

Key words: hippocampus; dentate gyrus; к opioids; endogenous opioids; dynorphin; long-term potentiation; mossy fibers; hilus; granule cell; guinea pig
The importance of the hippocampal formation in learning and memory mechanisms (Holland and Bouton, 1999) and the role of this region in certain forms of epilepsy (Sloviter, 1999) has greatly stimulated the analysis of hippocampal anatomy and synaptic physiology. The principal cells of the hippocampal formationpyramidal cells in hippocampus proper and granule cells in the dentate gyrus-receive complex excitatory and inhibitory synaptic inputs from various sources (Amaral and Witter, 1989). For example, the granule cells receive feedback and feedforward inhibition from interneurons within the dentate gyrus (Williamson et al., 1999) and feedback excitation from ipsilateral and contralateral hilar mossy cells (Scharfman and Schwartzkroin, 1988; Jackson and Scharfman, 1996). Feedback modulation of granule cell activity is generally thought to be caused by activation of hilar neurons by mossy fiber en passant contacts as well as by fine mossy fiber collaterals that are concentrated in the subgranular hilus (Frotscher et al., 1994). These mossy fiber collaterals have been noted to grow into the granule cell layer and inner molecular layer in various animal models of epilepsy (Okazaki et al., 1995; Bausch et al., 1998) and in hippocampal tissue from epileptic patients (Houser et al., 1990) and may thereby underlie

\footnotetext{
Received Aug. 13, 1999; revised March 8, 2000; accepted March 17, 2000.

This work was supported by National Institutes of Health (NIH) Grant DA00266 (G.W.T.), NIH Grant DA04123 (C.C.), an Aaron Diamond postdoctoral fellowship, and NIH Grants DE12738 (C.D.) and DA08259 (T.M.).

Correspondence should be addressed to Dr. Gregory Terman, Department of Anesthesiology, Box 356540, University of Washington, Seattle, WA 98195-6540. E-mail: gwt@u.washington.edu.

Copyright (c) 2000 Society for Neuroscience $\quad 0270-6474 / 00 / 204379-10 \$ 15.00 / 0$
}

some of the pathological excitation characteristics of epilepsy. Even in normal animals, however, there is evidence of granule cell-granule cell excitatory neurotransmission (MacVicar and Dudek, 1982; Molnar and Nadler, 1999), presumably via mossy fiber collaterals (Okazaki et al., 1999), which may have important implications for hippocampal physiology.

Previous studies have shown that mossy fiber collaterals within the hilus form a dense plexus of fibers that contain prodynorphinderived opioids (Zhang and Houser, 1999), suggesting that these $\kappa$ opioid peptides may function to regulate excitability in this region. We have previously investigated inhibitory effects of exogenous and endogenous $\kappa$ opioid agonists on perforant pathgranule cell excitatory neurotransmission and synaptic plasticity in the guinea pig hippocampal dentate gyrus (Wagner et al., 1993; Terman et al., 1994). These data suggest that endogenous dynorphins present in dense-core vesicles can be released from granule cell dendrites after high-frequency synaptic activation (Drake et al., 1994). Dynorphin release is calcium-dependent and requires activation of L-type calcium channels (Simmons et al., 1995). The released peptides activate $\kappa$ opioid receptors present on perforant path terminals and inhibit excitatory amino acid release, thereby inhibiting further excitatory neurotransmission and long-term potentiation (LTP) induction at this synapse (Simmons et al., 1994).

Similarly, we and others have reported that granule cell excitation releases dynorphin from granule cell axon terminals (Weisskopf et al., 1993; Simmons and Chavkin, 1996) in the CA3 region of the hippocampus. The effects of released dynorphin in the CA3 
region resemble dynorphin effects on perforant path terminals. Dynorphin binds to presynaptic $\kappa_{1}$ opioid receptors, providing feedback inhibition of both excitatory transmission and LTP (Weisskopf et al., 1993). However, in the CA3 region, the neuronal targets of released dynorphin are the mossy fiber terminals themselves, and dynorphin release in this region is not dependent on L-type calcium channel function, relying instead on $\mathrm{N}$-type calcium channel activity (Castillo et al., 1994; Simmons et al., 1995). In the present studies, we examined the effects of hilar mossy fiber collateral activation on granule cell excitability and compared the effects of $\kappa$ opioids on this activation with our previous results in CA3 and the dentate gyrus.

\section{MATERIALS AND METHODS}

Immunocytochemistry. Detailed methods for the anatomical data presented have been described elsewhere (Drake et al., 1994). In brief, adult male Hartley guinea pigs were deeply anesthetized with sodium pentobarbital and then perfused sequentially with (1) heparin-saline, (2) $3.75 \%$ acrolein and $2 \%$ paraformaldehyde in $0.1 \mathrm{M}$ phosphate buffer (PB), and (3) 2\% paraformaldehyde in $0.1 \mathrm{M} \mathrm{PB}$. Brains were removed, cut into 5-6 mm slices, and post-fixed for $30 \mathrm{~min}$ in the latter fixative. Horizontal sections $(40 \mu \mathrm{m})$ were then cut on a vibrating microtome (Vibratome), collected in PB, and incubated in $1 \%$ sodium borohydride in $0.1 \mathrm{M}$ PB to enhance immunoreactivity (Eldred et al., 1983).

As in our previous studies (Drake et al., 1994), polyclonal rabbit antiserum to dynorphin $\mathrm{A}_{1-8}$ was purchased from Peninsula Laboratories (Belmont, CA). The specificity of this antiserum was previously demonstrated using immunodot blots and immunoadsorption (Pickel et al., 1993). Polyclonal rabbit antisera against dynorphin $\mathrm{B}_{1-13}$ was a generous gift of Dr. Stanley Watson (Mental Health Research Institute, University of Michigan). The specificity of the dynorphin $\mathrm{B}_{1-13}$ antiserum has been demonstrated previously by self-blocking and cross-blocking adsorption experiments (Neal and Newman, 1989).

A modification of the avidin-biotin complex (ABC)-peroxidase technique (Hsu et al., 1981) was used. Briefly, sections were processed through the following incubations with continuous agitation: (1) a 1:8000 dilution of dynorphin $\mathrm{A}_{1-8}$ antiserum, 1:16,000 dilution of dynorphin $\mathrm{B}_{1-13}$ antiserum for $38-42 \mathrm{hr}$ at $4^{\circ} \mathrm{C},(2)$ biotinylated goat anti-rabbit IgG (1:400, Vector Laboratories, Burlingame, CA) for $30 \mathrm{~min}$, (3) avidinbiotin-peroxidase complex (Vectastain Elite kit, Vector) at double the recommended dilution for $30 \mathrm{~min}$, (4) 3,3'-diaminobenzidine (Aldrich, Milwaukee, WI) and hydrogen peroxide for $6 \mathrm{~min}$. All incubations were performed at room temperature unless noted. Antisera were diluted in $0.1 \mathrm{M}$ Tris-saline, $\mathrm{pH} 7.6$, with $0.1 \%$ bovine serum albumin, and sections were washed between incubations with $0.1 \mathrm{M}$ Tris-saline. To aid antibody penetration, for light microscopy $0.25 \%$ Triton $\mathrm{X}-100$ was included in the primary antibody diluent, and for electron microscopy the freeze-thaw technique (Descarries et al., 1992) was used.

Sections processed for light microscopy were mounted on gelatincoated slides, defatted and dehydrated through a graded series of alcohols and xylenes, and coverslipped in DPX (Aldrich). Tissue was examined and photographed on a Nikon Microphot microscope using brightfield and differential interference contrast optics. For electron microscopy, immunolabeled sections were fixed in $2 \%$ osmium tetroxide in $\mathrm{PB}$ for $1 \mathrm{hr}$ and embedded in EmBed 812 as described previously (Milner and Veznedaroglu, 1992). Regions through the granule cell and molecular layer of the dentate gyrus crest were selected in sections with morphological correspondence to slices used for electrophysiology (see Fig. 1). Ultrathin (70 nm) sections of this region were collected on copper grids and counterstained with uranyl acetate and lead citrate (Milner and Veznedaroglu, 1992). Sections from three animals were examined and photographed on a Philips 201 or a Philips CM10 electron microscope.

Electrophysiology. Hippocampal slices $(500 \mu \mathrm{m})$ were prepared as described previously (Terman et al., 1994) by decapitating and rapidly extracting the brain from 175-250 gm adult male Hartley guinea pigs (Simonsen Labs, Gilroy CA). Slices were cut in the horizontal plane using a Campden vibratome and placed in a heated $\left(34^{\circ} \mathrm{C}\right)$ perfusion chamber where they were superfused at $1 \mathrm{ml} / \mathrm{min}$ with Krebsbicarbonate buffer, $\mathrm{pH} 7.4$, containing (in mM): $\mathrm{NaCl} 125, \mathrm{KCl} 3, \mathrm{CaCl}_{2}$ $4, \mathrm{MgCl}_{2} 4, \mathrm{NaH}_{2} \mathrm{PO}_{4} 1.25, \mathrm{NaHCO}_{3} 26$, and glucose 10 saturated with $95 \% \mathrm{O}_{2} / 5 \% \mathrm{CO}_{2}$. Bicuculline $(10 \mu \mathrm{M})$ was bath-applied to all slices, unless otherwise specified, to block $\mathrm{GABA}_{\mathrm{A}}$ receptors and thereby isolate primarily excitatory responses.
Immediately before placement in the perfusion chamber, knife cuts were made in the slices to anatomically isolate either the hilar pathway or perforant path granule cell afferents. Knife cuts were made with a razor blade fragment held by a hemostat and were guided by the use of a dissecting microscope. The hilar pathway was selectively stimulated in slices containing a knife cut through the molecular layer of the dentate (abutting, but not including, the granule cell layer) to sever the perforant path axons (see Fig. $2 B$ ). Similarly, the perforant path was selectively stimulated by making a cut through the hilus, abutting the granule cell layer between the intended locations of the stimulating and recording electrodes (see Fig. 2A).

After at least $1 \mathrm{hr}$ of undisturbed superfusion for equilibration, extracellular recordings were begun in the dentate gyrus granule cell layer of a slice using a glass microelectrode (1-2 $\mu \mathrm{m}$ tip) filled with $\mathrm{NaCl}(3 \mathrm{~mm})$. Concentric bipolar stimulating electrodes (SNE 100, Kopf Instruments) were placed in the slice at a location relative to the knife cut, which allowed differential stimulation of hilar or perforant path granule cell afferents as detailed for each experiment below. Granule cell population response to a single $100 \mu \mathrm{A}$ square wave pulse of $0.3 \mathrm{msec}$ duration was measured peak to peak using a digitizing oscilloscope (Tektronix, Beaverton, OR), and the recording electrode was advanced to maximize this response. Stimuli of various intensities $(30-500 \mu \mathrm{A})$ were then administered in ascending order at $30 \mathrm{sec}$ intervals, and population response amplitudes were recorded. The stimulus intensity that evoked a halfmaximal granule cell population spike amplitude $\left(S_{1 / 2}\right)$ was chosen for subsequent test stimuli. $S_{1 / 2}$ test pulses were then given at $1 \mathrm{~min}$ intervals throughout the experimental period. Before each new tetanic stimulation or drug addition, the stimulus intensity for the test pulse was adjusted to continue evoking a half-maximal $\left(S_{1 / 2}\right)$ response, and at least five baseline test pulses were given. Thus, changes in responsiveness produced by experimental manipulations were based on changes from the baseline measures determined immediately before each manipulation.

Bath-applied drug effects were studied at equilibrium from 15-20 min after addition of drug to the Krebs-bicarbonate perfusate. Perfusion chamber volume measured $\sim 3 \mathrm{ml}$. Mean granule cell population amplitude responses to five perforant path test pulses (at $S_{1 / 2}$ ) given immediately before drug application were compared with the mean response to five test pulses of the same intensity given beginning $15 \mathrm{~min}$ after drug.

Perforant path-granule cell LTP was produced using high-frequency electrical stimulation as previously described (Terman et al., 1994). This stimulation consisted of three $100 \mathrm{msec}, 100 \mathrm{~Hz}$ trains of $0.3 \mathrm{msec}, 300$ $\mu \mathrm{A}$ pulses, given one train every $10 \mathrm{sec}$. Long-term potentiation was operationally defined as the mean change in population response amplitude to five test pulses given $30 \mathrm{~min}$ after either perforant path or mossy fiber collateral tetanic stimulation compared with the mean response to five test pulses given immediately before the tetanus.

In the experiments using local application of dynorphin, dynorphin B (100 $\mu \mathrm{M}$, in Krebs-bicarbonate buffer) was applied separately to either the subgranular zone of the hilus or to the outer half of the molecular layer through a glass pipette connected to a Picospritzer (General Valve, Fairfield, NJ). After a baseline response to electrical stimulation at the $S_{1 / 2}$ was established, dynorphin B was pressure-ejected into the tissue (20-40 psi, 50-200 msec duration), and the amplitude of the population response 1 min later was recorded. Raw data were converted to percentage of baseline values for analysis. In some slices, the $\kappa_{1}$-selective opioid receptor antagonist norbinaltorphimine $(\mathrm{nBNI})$ was added to the perfusate at least $15 \mathrm{~min}$ before dynorphin application both to test the $\kappa_{1}$ specificity of the locally applied dynorphin effects and to control for possible pressure artifacts.

In experiments investigating responses to endogenous dynorphin, hilar high-frequency stimulation (HFS) previously found to produce dynorphin release and inhibition of perforant path-granule cell neurotransmission (Wagner et al., 1993) was administered (six $1 \mathrm{sec}, 50 \mathrm{~Hz}$ trains of $0.3 \mathrm{msec}, 300 \mu \mathrm{A}$ pulses delivered one every other sec). After at least 10 min of stable baseline recording, hilar HFS was administered and then responses to granule cell afferent stimulation were recorded beginning 1 min after hilar HFS.

Except for the LTP experiments, all raw data were converted to percentage of baseline values. In the LTP experiments, raw data were converted to percentage potentiation by subtracting 100 from the percentage baseline values. Statistical analysis was performed on transformed data using between-subjects analyses of variance with NeumanKeuls tests for between group post hoc comparisons (Hays, 1973). A probability of $<0.05$ was chosen for statistically significant rejection of the null hypothesis. 

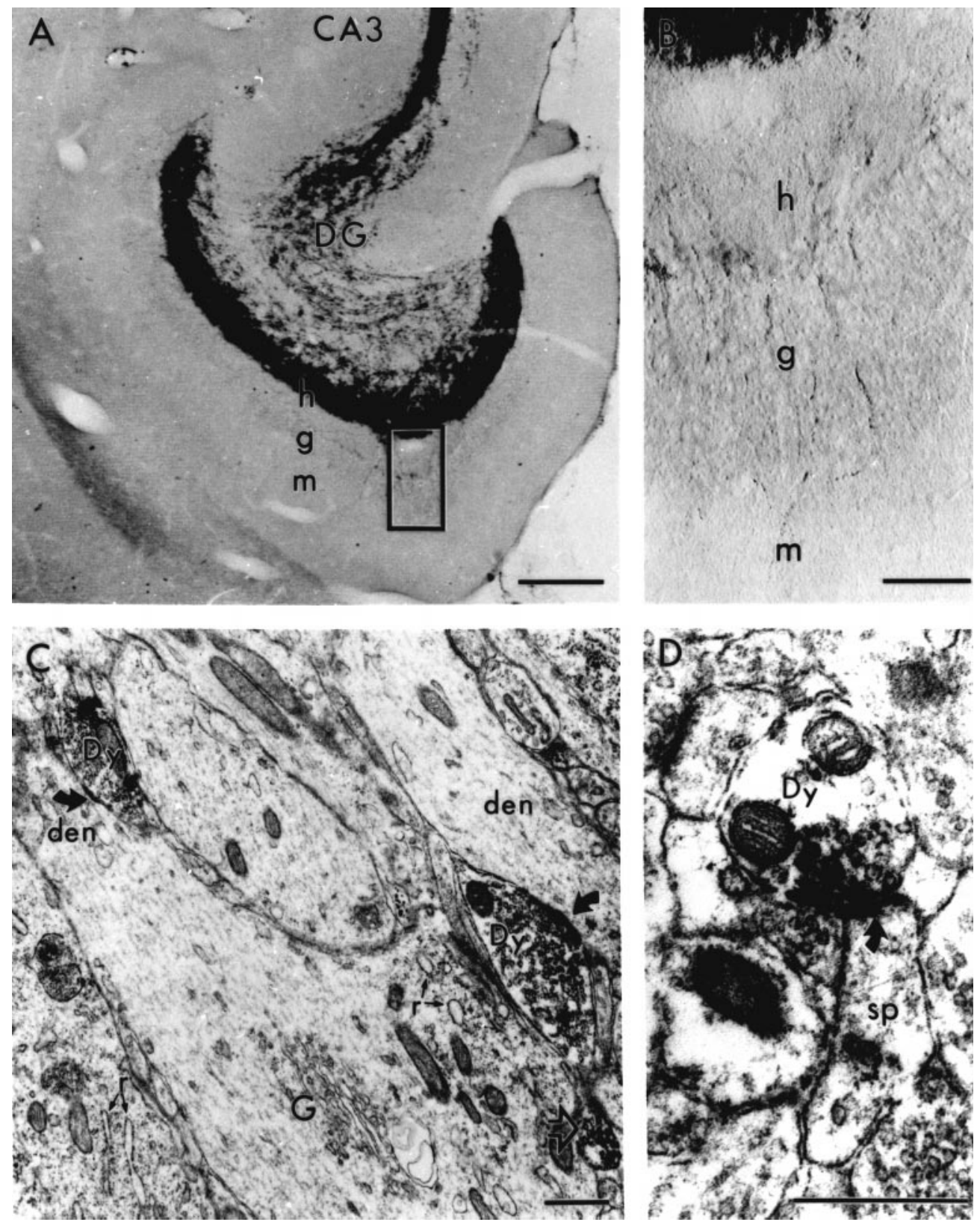

Figure 1. Light and electron microscopic localization of dynorphin-like immunoreactivity in dentate gyrus suggest that mossy fiber collaterals form excitatory synapses with granule cells. $A$, In the dentate gyrus, dynorphin-li is very dense in mossy fiber collaterals in the plexiform region of the hilus $(h)$ and in mossy fibers as they course to the CA3 region of the hippocampus. Some labeled processes are also present in the granule cell layer $(g)$ and innermost portion of the molecular layer $(m)$. $B$, Higher magnification of the boxed region in $A$ shows dynorphin-immunolabeled processes in the granule cell layer $(g)$, the inner molecular layer $(m)$, and the subgranular region of the hilus $(h) . C$, Two dynorphin-immunolabeled axon terminals $(D y)$ at the border between the granule cell and inner molecular layers form asymmetric synaptic specializations (curved arrows) with dendritic shafts (den). The dendritic shaft on the left is continuous with a nearby perikaryon, as indicated by the presence of Golgi apparatus $(G)$ and saccules of rough endoplasmic reticulum $(r)$. (For comparison, rough endoplasmic reticulum is also indicated in an adjacent granule cell perikaryon.) A small axon with dynorphin-li is also present (open arrow). D, A dynorphin-immunolabeled terminal ( $D y)$ forms an asymmetric synapse (curved arrow) with a small dendritic spine $(s p)$ in the inner molecular layer. Scale bars: $A, 250 \mu \mathrm{m} ; B, 50 \mu \mathrm{m}$; $C, D, 0.5 \mu \mathrm{m}$.
Materials. Bicuculline, U69,593, isradipine, and D-2-amino-5-phosphonovalerate (APV) were purchased from Sigma (St. Louis, MO). nBNI and 6-cyano-7-nitroquinoxaline-2,3-dione (CNQX) were purchased from Research Biochemicals International (Natick, MA). All drugs diluted from a concentrated stock solution were added to the perfusate in a 1:1000 dilution.

\section{RESULTS}

\section{Anatomical evidence for a direct excitatory granule cell to granule cell pathway}

As we and others have previously reported (McLean et al., 1987; Drake et al., 1994), intense dynorphin-like immunoreactivity (dynorphin-li) is present in the hilus of the guinea pig dentate gyrus (Fig. $1 A$ ). At higher magnification, dynorphinimmunolabeled processes are also evident within the granule cell layer and penetrate through this layer into the inner molecular layer (Fig. 1B), particularly at the crest of the dentate gyrus. Dynorphin-li is known to be in the mossy fibers (McGinty et al.,
1983), which originate from granule cells and course through the hilus toward CA3. Numerous mossy fiber collaterals are concentrated in the plexiform zone of the hilus, and some of these penetrate the granule cell layer and inner molecular layer (see also Stanfield, 1989; Wolfer and Lipp, 1995).

At the ultrastructural level, dynorphin-like immmunolabeling in the granule cell and inner molecular layers was localized to unmyelinated axons and small axon terminals (Fig. 1C,D), resembling mossy fiber collaterals (Claiborne et al., 1986). These dynorphin-labeled terminals formed asymmetric synapses with dendrites and perikarya. Granule cell perikarya were infrequently synaptically contacted by dynorphin-labeled terminals, whereas interneuron perikarya were more commonly contacted, as previously observed in other species (Ribak and Peterson, 1991). However, many dendritic targets of dynorphin-labeled terminals resembled granule cell dendrites. These were large dendritic shafts (1.0-2.0 $\mu \mathrm{m}$ in diameter) near the granule cell layer-inner 
molecular layer border (Fig. 1C) or dendritic spines in the inner molecular layer (Fig. 1D). Because asymmetric synapses have been previously correlated with excitatory transmission (Peters et al., 1991), these results provide anatomical evidence that a direct excitatory granule cell-granule cell pathway is present in the normal guinea pig. We next attempted to electrophysiologically characterize this pathway.

\section{Electrophysiological evidence of distinct hilar and perforant path granule cell afferents}

Stimulation either in the molecular layer (where perforant path and commissural afferents are concentrated) (Fig. $2 A, B$, electrode 2 ) or in the hilus (where mossy fiber collaterals, mossy cell axons, and some CA3 pyramidal cell axons provide recurrent excitatory afferents collectively referred to here as the hilar path) (Fig. 2A, $B$, electrode 3 ) evoked an extracellularly recorded synaptic response measured in the granule cell layer (data not shown). To better resolve the contributions of the perforant path and the hilar path, specific knife cuts were used (Fig. 2). Selective electrical stimulation of the perforant path, by a stimulating electrode placed in the molecular layer after a knife cut through the hilus, was effective in producing population responses measured in the granule cell layer (Fig. $2 A$, electrode 2). Surprisingly, a knife cut through the molecular layer, instead of the hilus, did not block the granule cell response to molecular layer stimulation (Fig. 2B, electrode 2). In contrast, molecular layer stimulation in slices with knife cuts through both the molecular layer and hilus did completely block granule cell population responses (data not shown). Thus, the strong granule cell response to molecular layer stimulation after the perforant path (molecular layer) cut suggests that an alternative excitatory input traveling through the hilus was effective in evoking a synaptic response.

Granule cell responses to selective activation of the perforant path were nearly unaffected by moving the stimulating electrode across the hippocampal fissure $(n=16)$ (Fig. $2 A$, electrode 1$)$. In contrast, hilar path responses were abolished $(n=8)$ (Fig. $2 B$, electrode 1$)$ at even very high-stimulus intensities $(500 \mu \mathrm{A})$. Granule cell responses to selective stimulation of the hilar pathway were only mildly affected by moving the stimulating electrode into the hilus $(n=5)$ (Fig. $2 B$, electrode 3$)$. However, such a move in stimulation site decreased granule cell responses to perforant path stimulation (data not shown) unless stimulus intensity was greatly increased $(n=5)$ (Fig. $2 A$, electrode 3$)$. Importantly, selective hilar path stimulation by an electrode in the molecular layer distal to the granule cell recording electrode (Fig. 2B, electrode 4) produced no discernable difference in granule cell population responses compared with those elicited by proximal hilar path stimulation $(n=5)$ (Fig. $2 B$, electrode 2$)$. These differential responses in molecular layer and hilar cut slices as a function of stimulating electrode placement suggest the validity of our knife cuts in electrophysiologically isolating the hilar and perforant path granule cell afferents. Specifically, the absence of a hilar pathway response to stimulation across the hippocampal fissure suggests that, unlike the perforant path, the hilar path does not originate across the fissure (e.g., in the entorhinal cortex). Moreover, the hilar path responses are bidirectional (i.e., similar responses can be elicited by stimulating distal and proximal to the recording electrode induced responses) (Fig. 2B, electrode 4 ). This makes the proposed hilar pathway studied here unlikely to simply represent aberrant perforant path fibers coursing through the hilus or granule cell layer en route to terminating in the outer two-thirds of the molecular layer with other perforant path fibers. Thus, it

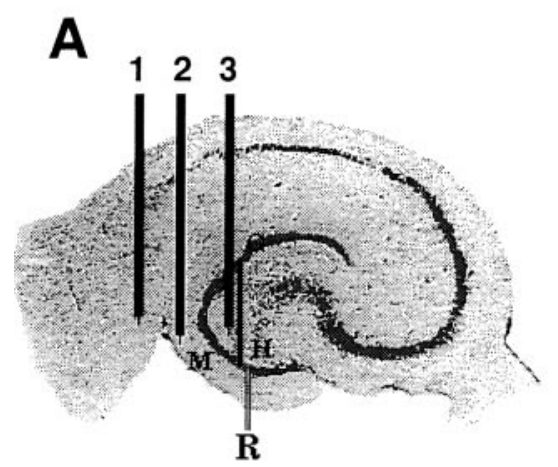

1)

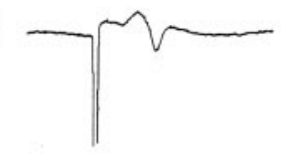

2)

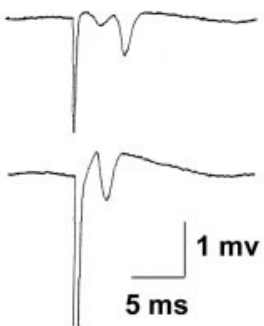

8

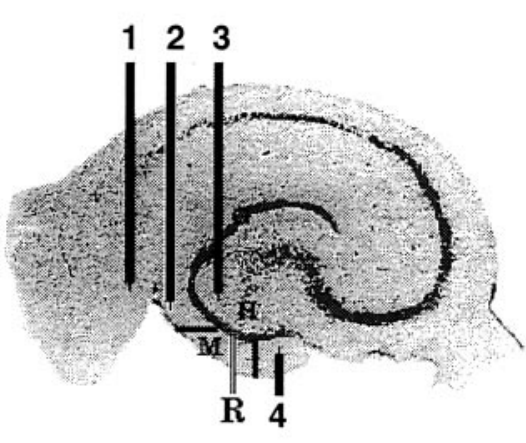

1)

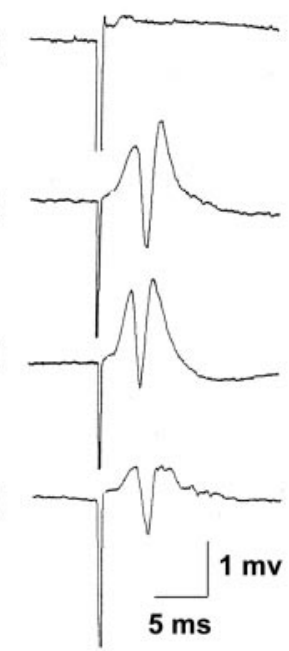

Figure 2. Stimulation site-specific differences between hilar and perforant path granule cell afferent pathways. Scanned cresyl violet-stained guinea pig hippocampal slice with superimposed schematics of the recording electrode $(R)$ in the granule cell layer $(G)$ and several stimulating electrode sites $(1-4)$ in the molecular layer $(M)$ or the hilus $(H)$ of the dentate gyrus. $A$, The hilar cut slice and representative examples of maximal population responses (peak to peak) to stimulation (at intensities up to $500 \mu \mathrm{A}$ ) at three sites stimulated sequentially as numbered. 1 , The stimulation site across the hippocampal fissure from the dentate required $150 \mu \mathrm{A}$ to achieve a maximal response. 2, Molecular layer stimulus produced a maximal response at $80 \mu \mathrm{A}$. 3, Hilar stimulus produced no population spike at a stimulus intensity of $150 \mu \mathrm{A}$ sufficient to evoke a maximal response without the cut (data not shown), but a response was evoked at $400 \mu \mathrm{A}$, presumably by current spread to the perforant path fibers in the molecular layer. $B$, The molecular layer cut slice and representative examples of maximal population responses to stimulation (at intensities up to $500 \mu \mathrm{A}$ ) at four sites stimulated sequentially as numbered. 1 , With the stimulation site across the hippocampal fissure from the dentate gyrus, even a $500 \mu \mathrm{A}$ stimulus produced no population response. 2, Molecular layer stimulation produced a maximal response at $200 \mu \mathrm{A}$. 3, Hilar stimulation produced a maximal response at $150 \mu \mathrm{A} .4$, Molecular layer stimulation distal to a second molecular layer cut produced a maximal response at $200 \mu \mathrm{A}$. Calibration: $1 \mathrm{mV}, 5 \mathrm{msec}$.

appears that the excitatory hilar path is anatomically and electrophysiologically distinct from the perforant path.

The independence of hilar and perforant path granule cell afferents, as defined by the knife cuts described above, was further examined by inducing LTP in one pathway and observing 


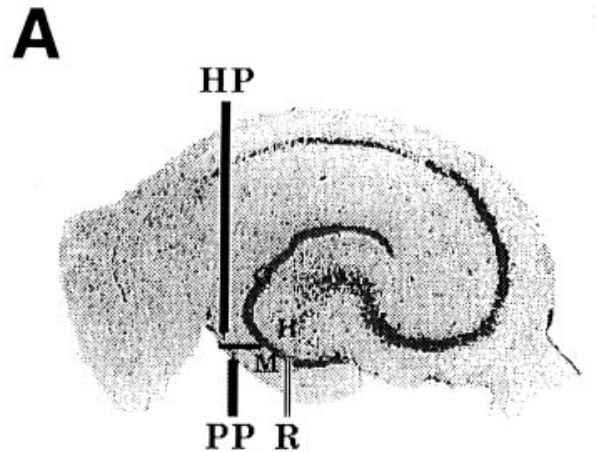

B

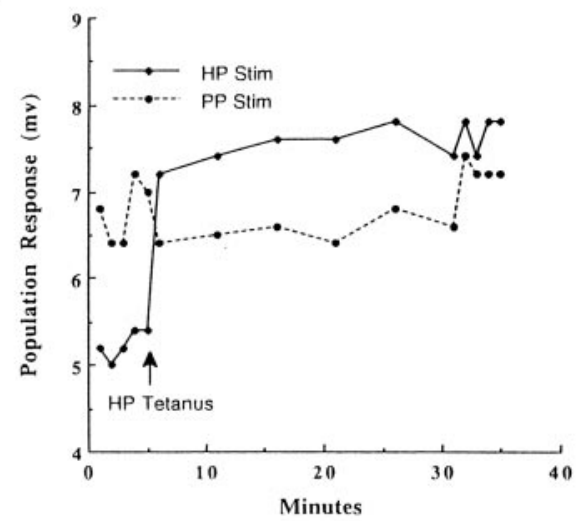

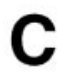

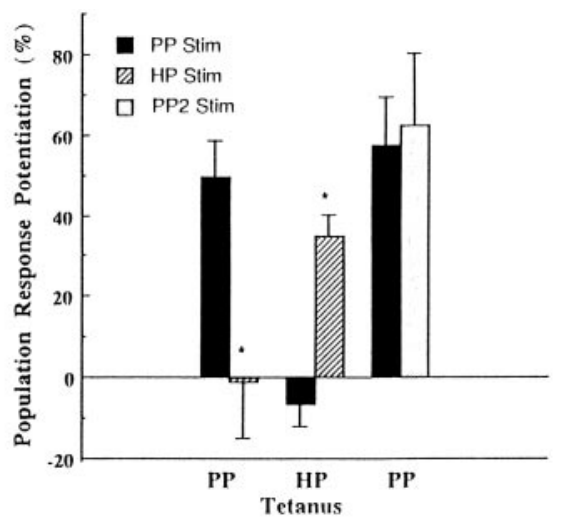

D

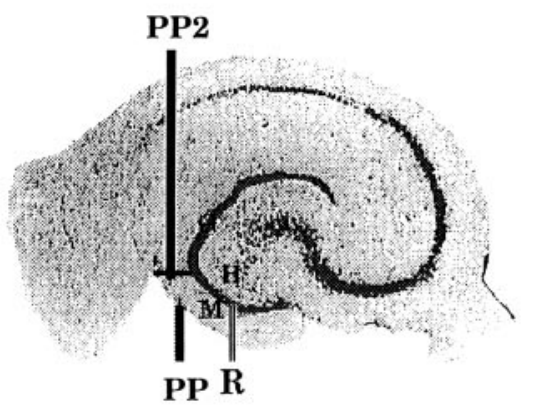

Figure 3. Lack of reciprocal potentiation of hilar and perforant path granule cell inputs. To test the hypothesis that hilar path $(H P)$ and perforant path $(P P)$ afferents independently excite granule cells, LTP of each pathway $(n=6)$ was induced with a tetanus, and changes were evaluated in the other pathway. Asterisk signifies statistical significance at $p<0.05$ level. $A$, Scanned cresyl violet-stained guinea pig hippocampal slice with a schematic of the recording electrode $(R)$ in the granule cell layer $(G)$, and hilar path $(H P)$ and perforant path $(P P)$ stimulating electrodes in the molecular layer $(M)$ of the dentate gyrus. $B$, Representative example of granule cell population responses to stimulation of hilar (HP Stim) and perforant (PP Stim) pathways before and $30 \mathrm{~min}$ after tetanic stimulation of the hilar path (HP Tetanus). In contrast to the sustained potentiation seen in the tetanized HP pathway (HP Stim), no change was evident in the perforant path (PP Stim). C, Tetanization of the perforant pathway (PP Tetanus) produced significantly more potentiation at $30 \mathrm{~min}$ (LTP) in the perforant path (PP Stim) than in the hilar path (HP Stim). Conversely, tetanization of the hilar path (HP Tetanus) produced significantly more LTP in the hilar path (HP Stim) than in the perforant path (PP Stim). In contrast to these results, responses to perforant path stimulation (PP Stim) after LTP induction (PP Tetanus) did not significantly differ from responses to a second stimulating electrode (PP2 Stim) placed in the perforant path (as in $D)$. $D$, Scanned cresyl violet-stained guinea pig hippocampal slice schematic of the recording electrode $(R)$ in the granule cell layer $(G)$ and two perforant path $(P P, P P 2)$ stimulating electrodes in the molecular layer $(M)$ of the dentate gyrus.

whether LTP also occurred in the other pathway. A failure to see such cross-potentiation would support the hypothesis that the pathways were distinct. In these studies, we used a single knife cut and two stimulating electrodes (Fig. 3A). LTP was induced (three $100 \mathrm{~Hz}, 100 \mathrm{msec}$ trains of $0.3 \mathrm{msec}, 300 \mu \mathrm{A}$ pulses given one train every $10 \mathrm{sec}$ ) in one pathway with one stimulating electrode, and then granule cell population responses to stimulation in both pathways were assessed in an alternating fashion every $30 \mathrm{sec}$ for 30 min (Fig. 3B). Tetanization (LTP induction) of the hilar path, for instance, produced significantly more LTP 30 min later in the hilar path than in the nontetanized perforant path (Fig. 3B,C). Similarly, tetanization of the perforant path produced significantly more LTP in the perforant path than in the nontetanized hilar path (Fig. 3B,C). These findings are consistent with the hypothesis that the two pathways provide separate afferent inputs to the granule cells. In contrast to both of these findings, control experiments using two separate perforant path stimulating electrodes (Fig. 3D) placed the same distance apart as in the previous experiments demonstrated LTP of responses from both elec- trodes (cross-potentiation), regardless of which electrode was used to tetanize the slice (Fig. 3C).

\section{Pharmacological properties of hilar and perforant path granule cell afferents}

Having provided evidence for the independence of the hilar and perforant path granule cell afferents, we began to investigate their individual neuropharmacological properties. We found, for example, that granule cell excitation by either pathway was unaffected by NMDA receptor blockade produced by bath-applied APV (25 $\mu \mathrm{M})$ (Fig. 4A). However, blockade of AMPA receptors by CNQX $(10 \mu \mathrm{M})$ almost completely eliminated any granule cell excitation by either pathway (Fig. $4 A$ ). As in the uncut slice, the $\kappa_{1}$ opiate agonist U69,593 $(1 \mu \mathrm{M})$ inhibited granule cell excitation by both the perforant and hilar pathways. The effects of U69,593 were blocked by the $\kappa_{1}$ antagonist nBN I (100 nm) (Fig. 4A). Similarly, LTP effects in both of the pathways were significantly inhibited by bath application of U69,593 in an nBNI-sensitive manner (Fig. $4 B$ ), much as in the uncut slice (Fig. 4B). APV significantly 

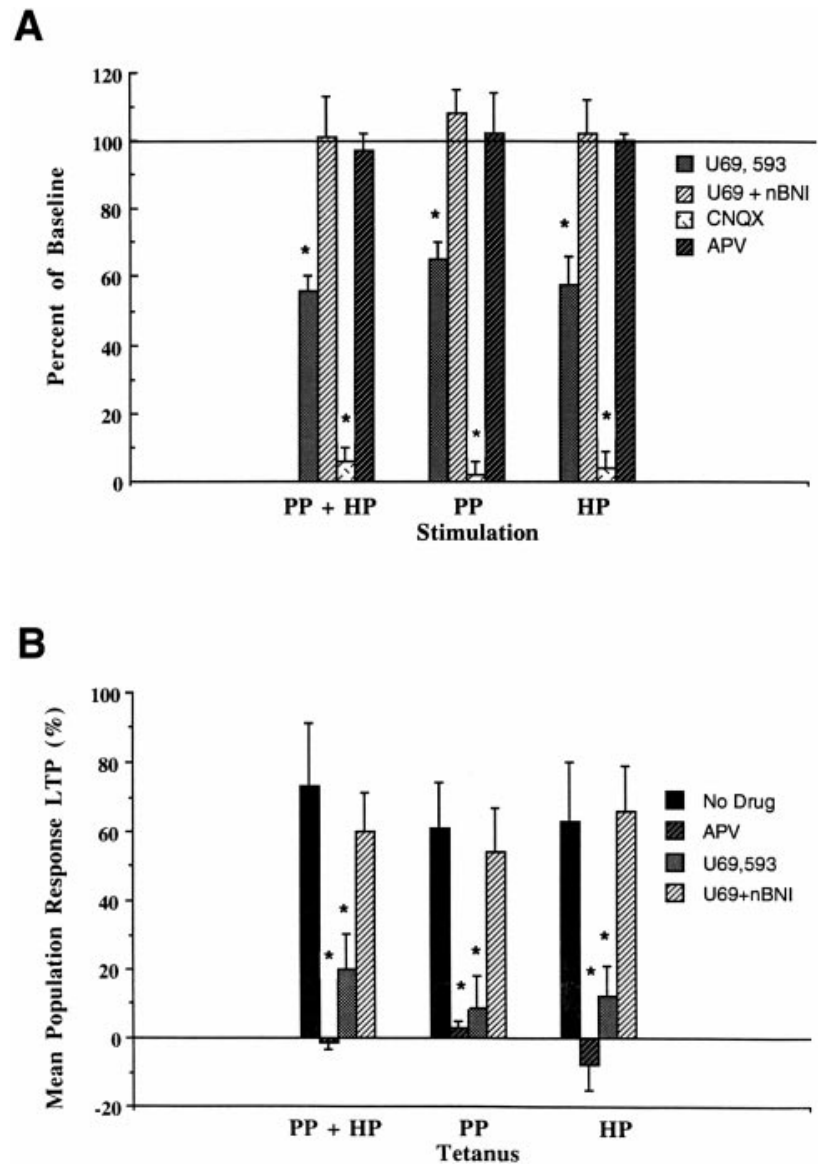

Figure 4. $\kappa$ inhibition of hilar and perforant path excitation of hippocampal dentate granule cells. $A$, Inhibition of neurotransmission by U69,593 in hilar and perforant pathways. Population responses from molecular layer stimulation in the uncut slice $(P P+H P$ Stimulation $)$ were significantly inhibited by U69,593 $(1 \mu \mathrm{M})$ compared with slices exposed to both U69,593 and nBNI $(100 \mathrm{~nm})(U 69+n B N I)$. The population response was also significantly inhibited by the AMPA antagonist CNQX $(10 \mu \mathrm{M})$, but was unaffected by the NMDA antagonist APV $(25 \mu \mathrm{M})$. In cut slices, neurotransmission in both perforant path (PP Stimulation) and hilar path (HP Stimulation) was also significantly inhibited by U69,593 in an nBNIsensitive manner. All responses were blocked by CNQX but were unaffected by APV. All groups include data from six slices. Asterisk signifies a significant difference from U69 $+n B N I$ controls. Cut $(n=4)$ and uncut $(n=3)$ slices exposed to nBNI alone showed no change from untreated control slices (data not shown) (see also Terman et al., 1994). B. Inhibition of LTP by U69,593 and APV in hilar and perforant pathways. LTP in the perforant (PP Tetanus) and hilar (HP Tetanus) pathways, as well as in uncut slices ( $P P+H P$ Tetanus), was significantly inhibited by the NMDA antagonist APV $(25 \mu \mathrm{M})$ and U69,593 $(1 \mu \mathrm{M})$ compared with No Drug control slices. The latter inhibition was blocked by coadministration of nBNI $(U 69+n B N I)$. All groups include data from six slices. Asterisk signifies a significant difference from No Drug controls. Cut $(n=4)$ and uncut $(n=3)$ slices exposed to nBNI alone showed no change from No Drug control slices (data not shown) (see also Terman et al., 1994).

inhibited LTP in both the hilar and perforant pathways (Fig. 4B), but it did not affect the amplitude of the response evoked by a single stimulation event (Fig. 4A).

\section{Hilar dynorphin inhibits hilar path granule cell excitation}

To study the sites of action for the inhibitory effects of $\kappa$ opioids in the dentate gyrus, the effects of local dynorphin application on population responses from perforant path and/or hilar path stimulation were measured. Dynorphin B $(100 \mu \mathrm{M})$ was pressure-
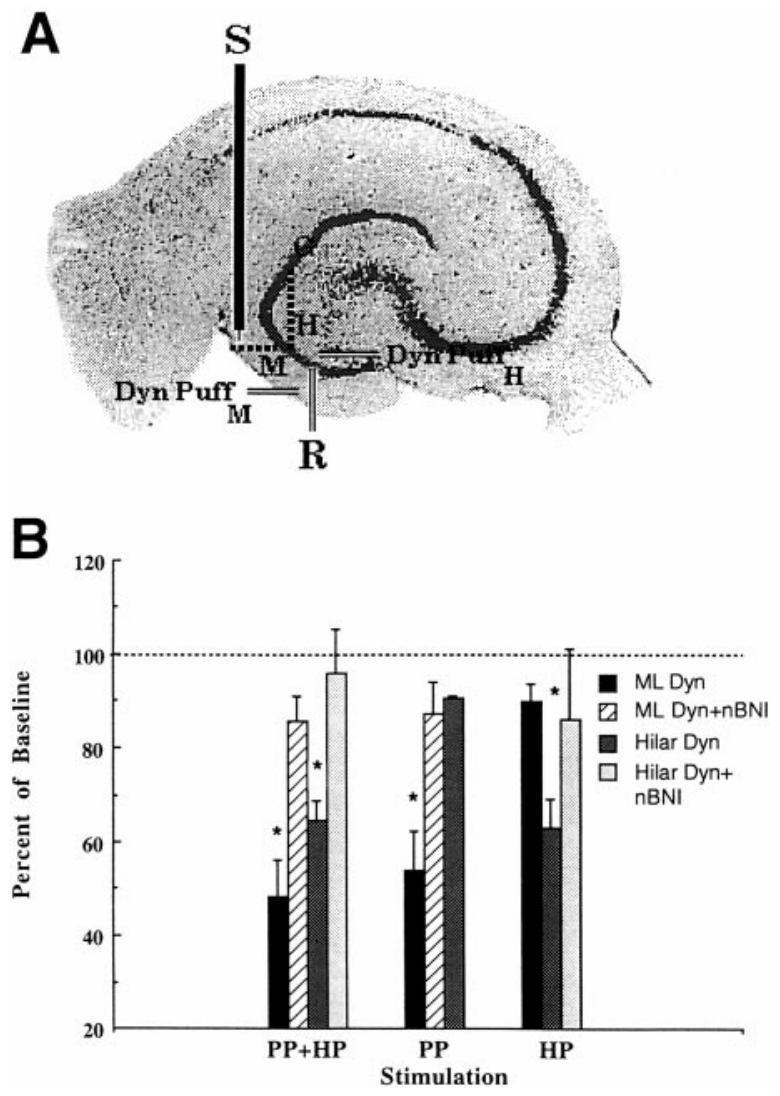

Figure 5. Selective inhibition of perforant path and hilar path neurotransmission by molecular layer and hilar administered dynorphin, respectively. To evaluate the sites of action for $\kappa$ opioid inhibitory effects in the dentate, the effects of locally applied dynorphin were studied on perforant path and hilar path stimulation-induced population responses. Dynorphin B $(100 \mu \mathrm{M})$ was pressure-ejected (20-40 psi, 50-200 msec) in the molecular layer $(M)$ or subgranular hilus $(H)$, and the effects on hilar and/or perforant path neurotransmission were examined. $A$, Scanned cresyl violet-stained guinea pig hippocampal slice schematic of the recording electrode $(R)$ in the granule cell layer $(G)$ and a stimulating electrode $(S)$ in the molecular layer $(M)$ of the dentate gyrus. For any one slice, a hilar or a molecular layer cut (represented by the two dashed lines) or no cut was made, and a pressure injection pipette was placed into both the molecular layer (Dyn Puff ${ }_{M}$ ) and hilus (Dyn Puff ${ }_{H}$ ) sequentially in a counterbalanced order across slices. Specific stimulation of the perforant path or the hilar path was performed as before, depending on which of the pathways was cut. Both pathways were assumed to be stimulated in the uncut slice. B, Dynorphin B puffs inhibited granule cell responses in the uncut $(P P+H P$ Stimulation $)$ slice when puffed in either the molecular layer (ML Dyn; $n=8$ ) or the hilus (Hilar Dyn; $n=18$ ). In cut slices, however, dynorphin B puffs inhibited PP-induced responses (PP Stimulation) only when puffed in the molecular layer $(M L D y n ; n=4)$ and not the hilus (Hilar Dyn; $n=4$ ). Conversely, only dynorphin puffs in the hilus $($ Hilar Dyn; $n=5)$ and not the molecular layer $(M L D y n ; n=7)$ inhibited hilar path activity (HP Stimulation). In all groups of slices, nBNI (100 nM) coadministration by bath application significantly attenuated the inhibitory effects of puffed dynorphin $(n=3)$. Asterisk signifies a statistical difference between that group and nBNI-coadministered controls.

ejected (20-40 psi, 50-200 msec) either in the outer molecular layer or in the subgranular hilus (Fig. $5 A$ ). In the uncut slice, local administration of dynorphin in either the molecular layer or the hilus greatly reduced granule cell population responses $1 \mathrm{~min}$ after administration (Fig. 5B). This effect was significantly attenuated by bath-administered nBN I (Fig. $5 B$ ), suggesting $\kappa_{1}$ opioid receptor mediation. In contrast, in cut slices only dynorphin puffed in the outer molecular layer, but not in the hilus, inhibited 

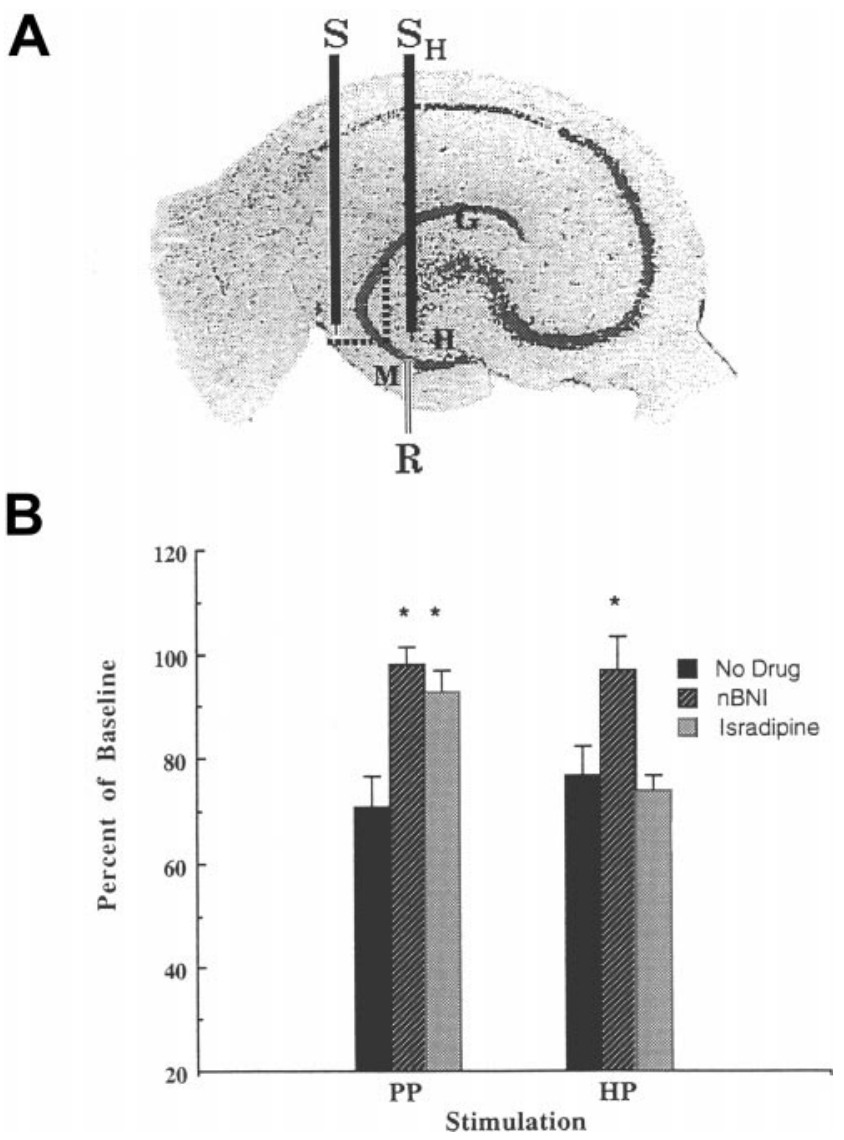

Figure 6. Dynorphin release from perforant path but not hilar path stimulation is dependent on L-type calcium channels. $A$, Scanned cresyl violet-stained guinea pig hippocampal slice schematic of the recording electrode $(R)$ in the granule cell layer $(G)$ and a stimulating electrode $(S)$ in the molecular layer $(M)$ of the dentate gyrus. A second stimulating electrode was placed in the hilus $\left(S_{H}\right)$ to administer high-frequency stimulation to that region $(1 \mathrm{sec}$ of $50 \mathrm{~Hz}, 300 \mu \mathrm{A}, 0.3 \mathrm{msec}$ pulses given six times at $0.5 \mathrm{~Hz}$ ), a stimulus that we have previously found to release dynorphin in the dentate gyrus (Drake et al., 1994; Simmons et al., 1995). For any one slice, a hilar or a molecular layer cut (represented by the two dashed lines) was made. B, Hilar HFS produced an inhibition of population responses $1 \mathrm{~min}$ post-HFS to perforant path stimulation (PP Stimulation). This inhibition was significantly antagonized by pretreatment with $\mathrm{nBNI}(100 \mathrm{nM})$ or by the L-type calcium channel blocker isradipine (5 $\mu \mathrm{M})$. In contrast, the HFS-induced inhibition of hilar path responses (HP Stimulation) was antagonized by nBNI but was unaffected by isradipine. $n=6$ in all groups. Asterisk signifies a statistical difference from No Drug controls.

perforant path-induced granule cell excitation in an nBNIsensitive manner (Fig. 5B). Moreover, in separate cut slices, only dynorphin applied in the hilus, but not in the outer molecular layer, inhibited hilar path-induced excitation in an nBN I-sensitive manner (Fig. 5B). This observation further supports the hypothesis that the pathways are distinct. Thus, dynorphin appears capable of inhibiting granule cell excitation produced by either hilar or perforant pathways, but the site of action for this inhibition appears to be pathway specific and therefore probably presynaptic.

The demonstration that exogenous opioids inhibit excitatory hilar path neurotransmission suggests that endogenous dynorphins present in the mossy fiber collaterals may regulate this path. We have reported that high-frequency stimulation within the hilus (Fig. $6 A$, electrode $S_{H}$ ) can release dynorphin from granule
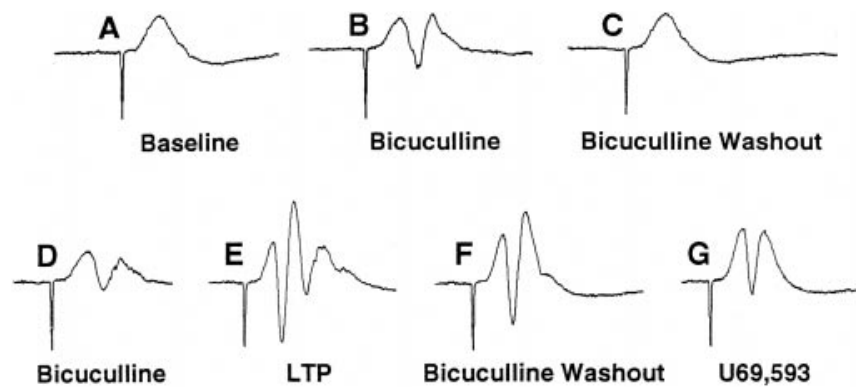

Figure 7. Tonic $\mathrm{GABA}_{\mathrm{A}}$-mediated inhibition of the hilar pathway is overcome by LTP. Representative oscilloscope traces of a response to stimulation of the hilar pathway $(A)$ at baseline, $(B)$ after bicuculline, $(C)$ after bicuculline washout ( $45 \mathrm{~min}),(D)$ after bicuculline reapplication, $(E)$ after LTP induction, $(F)$ after bicuculline washout again, and $(\mathrm{G})$ after U69,593.

cells (Wagner et al., 1991, 1993). Dynorphin released by this method reduced the amplitude of the perforant path-evoked response in an nBNI-sensitive manner (Fig. 6B), as we had demonstrated previously. Stimulation of dynorphin release also reduced the granule cell response evoked by hilar path activation in an nBNI-sensitive manner (Fig. 6B). We have shown that the source of dynorphin that inhibits perforant path excitation is the granule cell dendrites (Drake et al., 1994). However, the source of dynorphin responsible for controlling the hilar input is almost certainly in the hilus because only application of dynorphin in the hilus is effective in inhibiting this pathway. Thus, dynorphin released from mossy fiber axon collaterals is likely to be responsible for the hilar path inhibition observed.

Site-specific inhibition of neurotransmission and LTP by endogenous $\kappa$ opioids in the two granule cell afferent pathways is mirrored by our previous findings of the effects of $\kappa$ opioids in the dentate gyrus molecular layer and in the CA3 region. We previously found that dynorphin release from granule cell dendrites could be distinguished from axonal release of dynorphin in the CA3 region by its sensitivity to L-type calcium channel antagonists (Simmons et al., 1995). We therefore investigated whether dynorphin release from the dentate granule cell axon collaterals depended on L-type calcium channels. The L-type calcium channel blocker isradipine $(5 \mu \mathrm{M})$ blocked the dynorphin-mediated inhibition of perforant path neurotransmission (Fig. 6B). In contrast, inhibitory effects of endogenous dynorphin on hilar path neurotransmission were unaffected by isradipine, suggesting that the release of dynorphin from mossy fiber axon collaterals is not dependent on L-type calcium channels. These results are similar to the axonal dynorphin release from mossy fibers measured in the CA3 region (Simmons et al., 1995).

\section{GABA normally inhibits hilar path granule cell excitation}

All of the experiments described thus far in the cut slice, as in much of our previous work in the uncut slice, were conducted with bicuculline in the perfusate and thus in the disinhibited slice. We found little difference between normal and disinhibited slices in the maximum amplitude or shape of the granule cell population responses in cut or uncut perforant path stimulated slices (data not shown). However, we have been unable to find even one example thus far of a hilar path-mediated granule cell population response in the guinea pig slice without bicuculline pretreatment, regardless of the intensity of stimulation (Fig. $7 A-C$ ). This is perhaps not surprising considering the extensive inhibitory cir- 
cuitry known to exist in the guinea pig dentate, making LTP and various seizure models (e.g., kindling and pilocarpine) difficult to study in this species without disinhibition. Interestingly, however, we find that the contribution of the hilar pathway to granule cell responses, even in the guinea pig slice without disinhibition, can show considerable plasticity. For example, if during a brief period of $\mathrm{GABA}_{\mathrm{A}}$ receptor blockade by bicuculline (Fig. 7D) LTP induction takes place in the hilar pathway (Fig. 7E), reestablishment of inhibition (washout of bicuculline) no longer masks the granule cell population response to hilar stimulation (Fig. $7 F$ ). These findings suggest that although the hilar path may contribute little to the normal granule cell response in the guinea pig hippocampus (at least in vitro), a brief period of disinhibition via neural, pharmacological, or metabolic means can have longlasting effects in unmasking hilar path excitatory influences. Importantly, $\kappa$ opioids, even in this hyperexcitable state, can still inhibit granule cell excitation from the hilar pathway (Fig. 7G).

\section{DISCUSSION}

In this paper, we have provided anatomical and electrophysiological evidence in the guinea pig for the existence of an excitatory input to the dentate granule cells that is anatomically and pharmacologically distinct from the perforant path. This pathway, coursing through the hilus, can be inhibited by dynorphins released from mossy fiber collaterals in the hilus. These findings give further support for an important role of dynorphin in modulating hippocampal excitability and neuroplasticity in the mammalian brain.

\section{Hilar afferents mediating granule cell excitation}

The hilus of the dentate gyrus has become a focus of considerable research on the homeostatic regulation of hippocampal excitability. Our ultrastructural data suggest that there is a direct connection between mossy fiber collaterals and granule cells in the normal guinea pig dentate gyrus. Indirect connections between granule cells via excitatory mossy cells in the hilus have also been demonstrated, although most of these studies have been performed in rats. Granule cell axon collaterals innervate mossy cells in the hilus, and anatomical (Wenzel et al., 1997) and electrophysiological (Scharfman, 1995) evidence suggests that mossy cells activate both granule cells and inhibitory interneurons. However, elegant double-electrode intracellular electrophysiology experiments by Scharfman (1995) have found that mossy cell excitatory connections to granule cells are more rare in slice preparations than anatomical studies might indicate (Molnar and Nadler, 1999), perhaps because most of these connections are formed outside the plane of the transverse hippocampal slice (Buckmaster et al., 1996). Thus our ability to routinely observe granule cell excitation with hilar path stimulation suggests that direct or indirect mossy cell activation is not solely responsible for our effects, strengthening the possibility that granule cell-granule cell connections may be of primary importance.

Another excitatory input to granule cells that is potentially involved in the hilar pathway is the projection from the supramammillary region of the hypothalamus, which forms excitatorytype synapses on the proximal dendrites and somata of granule cells (Dent et al., 1983; Nitsch and Leranth, 1994). In vivo experiments in rats have demonstrated a potentiation of perforant path excitation by this pathway and a correlation in activity with dentate theta rhythm (Segal, 1979; Dahl and Winson, 1986; Carre and Harley, 1991). Evidence that supramammillary afferents contain immunoreactivity for $\kappa$ opiate receptors (Drake et al., 1997) gives credence to the idea that this pathway is also under dynorphin control and underscores the importance of dynorphin modulation of excitability in guinea pig dentate gyrus. Nevertheless, it is not clear that stimulation of only the hilus (and not the perforant path) would activate these supramammillary afferents consistently and selectively as seen in the present hilar stimulation studies.

Thus the rich mossy fiber collateral system, running from dentate granule cells through the hilus and in some cases (Fig. 1) forming recurrent excitatory connections to other granule cells, is the likely substrate for the hilar stimulation-induced granule cell excitation studied here. Similar recurrent excitation is already well described in the CA3 (Christian and Dudek, 1988) and CA1 (Perez et al., 1996) regions of the hippocampus as well as in several neocortical brain areas (Wong et al., 1986). Indeed, in the dentate gyrus recurrent excitation has already been suggested to play a role in certain models of epilepsy (Sutula et al., 1988; Cronin et al., 1992; Simmons et al., 1997; Patrylo and Dudek, 1998; Okazaki et al., 1999). Even in the nonepileptic rat, however, in vivo (Bekenstein and Lothman, 1991; Hetherington et al., 1994) and in vitro (Jackson and Scharfman, 1996) electrophysiological evidence supports the existence of recurrent excitatory fibers coursing through the hilus. Moreover, recent reports from Nadler's group (see also (MacVicar and Dudek, 1982) demonstrating granule cell-granule cell excitatory transmission in the rat (Molnar and Nadler, 1999; Okazaki et al., 1999) suggests that mossy fiber collaterals are most likely to mediate such recurrent excitation, analogous to our current conclusions in the guinea pig.

\section{Dynorphin-sensitive granule cell recurrent excitation is distinct from other dynorphin-sensitive granule cell excitation}

This mossy fiber collateral excitatory hilar input to granule cells is anatomically and neurochemically distinct from the perforant path inputs as demonstrated by the differential effects of knife cuts, the independence of LTP, and the site-specific dynorphinmediated inhibition of the two pathways. Both hilar and perforant path granule cell afferents do release excitatory amino acids and are capable of NMDA-dependent LTP. Clearly, similarities between the mossy fiber terminals in CA3 and those proposed for the hilar path do not extend to NMDA mediation of LTP. The NMDA independence of mossy fiber LTP in CA3 is well described in guinea pigs (Williams and Johnston, 1996). This difference in LTP neurochemistry at two axon terminal sites of the same cells would argue for a primarily postsynaptic mechanism of LTP in this system.

Another difference between perforant path and hilar path activity is the complete suppression of excitatory population responses to hilar stimulation unless the slice is disinhibited. This finding could be attributable to proportionately more inhibitory circuitry than excitatory circuitry remaining intact in vitro or to an extraordinary amount of inhibition present in the guinea pig hippocampus. In either event, it raises the issue of whether the hilar pathway has any importance in normal hippocampal function. In this regard, it is important to note that Hetherington et al. (1994) also reported an ipsilateral granule cell excitatory hilar path that shows NMDA-mediated LTP. Their studies did not include the disinhibition required in our studies to observe the hilar path effects but differed from ours in using rats and in vivo recordings. Jackson and Scharfman (1996) have also described a granule cell excitatory pathway in the rat hilus in vitro without disinhibiting the slice, suggesting a species difference between 
rats and guinea pigs. In guinea pigs, our present studies suggest that even if the hilar path is normally inhibited, a brief period of disinhibition may allow plastic changes to take place that override the inhibition, allowing excitation where there had been none before. Such periods of decreased inhibition might occur with various stimuli, including activation of disinhibitory neural circuitry, anoxia, trauma, or exposure to certain drugs. This unmasking of additional excitatory pathways could represent a mechanism for the development of long-lasting hyperexcitable states, perhaps mediating certain forms of learning and memory or, more ominously, providing a substrate for the development of epilepsy.

\section{Role of $\kappa$ opioid-sensitive recurrent excitation in epileptogenesis}

$\kappa$ opioids have been found to have therapeutic effects in various laboratory models of epilepsy (Tortella et al., 1986; Przewlocka et al., 1995; Bausch et al., 1998). The present studies add to previous reports by ourselves and others that $\kappa$ opioids can inhibit excitatory neurotransmission and synaptic plasticity involving granule cells in dentate molecular layer, CA3, and now in the hilar path. Furthermore, endogenous $\kappa$ opioids, namely, the dynorphins released from granule cells by intense granule cell stimulation, appear to provide feedback inhibition of further granule cell excitation (Wagner et al., 1993; Weisskopf et al., 1993). We have previously documented this in dentate molecular layer where dendritic stores of dynorphin are released and pass retrogradely to inhibit further granule cell excitation by binding to presynaptic $\kappa$ receptors and inhibiting glutamate release from perforant path terminals (Drake et al., 1994; Simmons et al., 1994). We have found this dendritic dynorphin release to be blocked by L-type calcium channel blockers (Simmons et al., 1995). L-type voltagedependent calcium channels have relatively long open times and large unitary conductances. This may be ideal for the large calcium fluxes likely to be necessary for neuropeptide release at nonclassical synapses where calcium channel density is lower. Moreover, the large calcium fluxes necessary for neuropeptide release may account for the intense stimulation required to produce such release in dynorphinergic (Wagner et al., 1991; Terman et al., 1994) and other systems (Lundberg et al., 1994). In contrast to dendritically released dynorphin, dynorphin released from axonal stores in both CA3 and hilus appears not to be dependent on L-type calcium channels, relying instead, at least in CA3, on N-type calcium channels (Simmons et al., 1995). As mentioned previously, dynorphin released from axonal stores appears to be suitably located to provide presynaptic inhibitory feedback of activated responses in $\mathrm{CA} 3$ or the dentate granule cell layer. Although precise anatomical localization of $\kappa$ receptors in these areas is not complete, electrophysiological studies of CA3 localize these receptors to granule cell axon terminals (Weisskopf et al., 1993).

The inhibition of granule cell recurrent excitation may have important physiological implications in seizure pathogenesis. $\mathrm{Nu}-$ merous studies have reported increased mossy fiber collateral sprouting in various animal models of epilepsy (Okazaki et al., 1995; Bausch et al., 1998; Patrylo and Dudek, 1998; Sutula et al., 1998) and in hippocampal tissue from epileptic patients (Houser et al., 1990; Zhang and Houser, 1999). Such mossy fiber sprouting clearly provides an anatomical basis for the loss of normal inhibitory interneuronal controls and underlines the importance of the pathway studied in the present experiments. In our studies of the pilocarpine model of epilepsy in rats, mossy fiber collateral sprouting is correlated both with seizures (Bausch et al., 1998) and with granule cell "giant EPSCs" in slices disinhibited by bicuculline (Simmons et al., 1997). Interestingly, inhibition of granule cell excitation by $\kappa$ opioids increases concurrently with mossy fiber collateral sprouting (Simmons et al., 1997; Bausch et al., 1998), supporting the idea that such drugs might be highly suited for therapy of certain forms of temporal lobe epilepsy.

\section{REFERENCES}

Amaral DG, Witter MP (1989) The three-dimensional organization of the hippocampal formation: a review of anatomical data. Neuroscience 31:571-591.

Bausch SB, Esteb TM, Terman GW, Chavkin C (1998) Administered and endogenously released kappa opioids decrease pilocarpine-induced seizures and seizure-induced histopathology. J Pharmacol Exp Ther 284:1147-1155.

Bekenstein JW, Lothman EW (1991) Electrophysiological characterization of associational pathway terminating on dentate gyrus granule cells in the rat. Hippocampus 1:399-404.

Buckmaster PS, Wenzel HJ, Kunkel DD, Schwartzkroin PA (1996) Axon arbors and synaptic connections of hippocampal mossy cells in the rat in vivo. J Comp Neurol 366:271-292.

Carre GP, Harley CW (1991) Population spike facilitation in the dentate gyrus following glutamate to the lateral supramammillary nucleus. Brain Res 568:307-310.

Castillo PE, Weisskopf MG, Nicoll RA (1994) The role of $\mathrm{Ca}^{2+}$ channels in hippocampal mossy fiber synaptic transmission and long-term potentiation. Neuron 12:261-269.

Christian EP, Dudek FE (1988) Characteristics of local excitatory circuits studied with glutamate microapplication in the CA3 area of rat hippocampal slices. J Neurophysiol 59:90-109.

Claiborne BJ, Amaral DG, Cowan WM (1986) A light and electron microscopic analysis of the mossy fibers of the rat dentate gyrus. J Comp Neurol 246:435-458.

Cronin J, Obenaus A, Houser CR, Dudek FE (1992) Electrophysiology of dentate granule cells after kainate-induced synaptic reorganization of the mossy fibers. Brain Res 573:305-310.

Dahl D, Winson J (1986) Influence of neurons of the parafascicular region on neuronal transmission from perforant pathway through dentate gyrus. Brain Res 377:391-396.

Dent JA, Galvin NJ, Stanfield BB, Cowan WM (1983) The mode of termination of the hypothalamic projection to the dentate gyrus. Brain Res 258:1-10.

Descarries L, Soghomonian J-J, Garcia S, Doucet G, Bruno JP (1992) Ultrastructural analysis of the serotonin hyperinnervation in adult rat neostriatum following neonatal dopamine denervation with 6-hydroxydopamine. Brain Res 569:1-13.

Drake CT, Terman GW, Simmons ML, Milner TA, Kunkel DD, Schwartzkroin PA, Chavkin C (1994) Dynorphin opioids present in dentate granule cells may function as retrograde inhibitory neurotransmitters. J Neurosci 14:3736-3750.

Drake CT, Chavkin C, Milner TA (1997) $\kappa$ opioid receptor-like immunoreactivity is present in substance P- containing subcortical afferents in guinea pig dentate gyrus. Hippocampus 7:36-47.

Eldred WD, Zucker C, Karten HJ, Yazulla S (1983) Comparison of fixation and penetration enhancement techniques for use in ultrastructural immunocytochemistry. J Histochem Cytochem 31:285-292.

Frotscher M, Soriano E, Misgeld U (1994) Divergence of hippocampal mossy fibers. Synapse 16:148-160.

Hays WL (1973) Statistics for the social sciences. New York: Holt, Rinehart and Winston.

Hetherington PA, Austin KB, Shapiro ML (1994) Ipsilateral associational pathway in the dentate gyrus: an excitatory feedback system that supports $N$-methyl-D-aspartate-dependent long-term potentiation. Hippocampus $4: 422-438$.

Holland PC, Bouton ME (1999) Hippocampus and context in classical conditioning. Curr Opin Neurobiol 9:195-202.

Houser CR, Miyashiro JE, Swartz BE, Walsh GO, Rich JR, DelgadoEscueta AV (1990) Altered patterns of dynorphin immunoreactivity suggest mossy fiber reorganization in human hippocampal epilepsy. J Neurosci 10:267-282.

Hsu SM, Raine L, Fanger H (1981) Use of avidin-biotin-peroxidase complex $(\mathrm{ABC})$ in immunoperoxidase techniques: a comparison be- 
tween $\mathrm{ABC}$ and unlabeled antibody (PAP) procedures. J Histochem Cytochem 29:577-580.

Jackson MB, Scharfman HE (1996) Positive feedback from hilar mossy cells to granule cells in the dentate gyrus revealed by voltage-sensitive dye and microelectrode recording. J Neurophysiol 76:601-616.

Lundberg JM, Franco-Cereceda A, Lou Y-P, Modin A, Pernow J (1994) Differential release of classical transmitters and peptides. In: Molecular and cellular mechanisms of neurotransmitter release (Stjarne L, Greengard P, Grillner S, Hokfelt T, Ottoson D, eds). New York: Raven.

MacVicar BA, Dudek FE (1982) Electrotonic coupling between granule cells of rat dentate gyrus: physiological and anatomic is contained within hippocampal mossy fibers: immunocytochemical alterations after kainic acid administration and colchicine-induced neurotoxicity. Proc Natl Acad Sci USA 80:589-593.

McLean S, Rothman RB, Jacobson AE, Rice DC, Herkenham M (1987) Distribution of opiate receptor subtypes and enkephalin and dynorphin immunoreactivity in the hippocampus of squirrel, guinea pig, rat, and hamster. J Comp Neurol 255:497-510.

Milner TA, Veznedaroglu E (1992) Ultrastructural localization of neuropeptide Y-like immunoreactivity in the rat hippocampal formation. Hippocampus 2:107-125.

Molnar P, Nadler JV (1999) Mossy fiber-granule cell synapses in the normal and epileptic rat dentate gyrus studied with minimal laser photostimulation. J Neurophysiol 82:1883-1894.

Neal Jr CR, Newman SW (1989) Prodynorphin peptide distribution in the forebrain of the Syrian hamster and rat: a comparative study with antisera against dynorphin $\mathrm{A}$, dynorphin $\mathrm{B}$, and the $\mathrm{C}$-terminus of the prodynorphin precursor molecule. J Comp Neurol 288:353-386.

Nitsch R, Leranth C (1994) Substance P-containing hypothalamic afferents to the monkey hippocampus: an immunocytochemical, tracing, and coexistence study. Exp Brain Res 101:231-240.

Okazaki MM, Evenson DA, Nadler JV (1995) Hippocampal mossy fiber sprouting and synapse formation after status epilepticus in rats: visualization after retrograde transport of biocytin. J Comp Neurol 352:515-534.

Okazaki MM, Molnar P, Nadler JV (1999) Recurrent mossy fiber pathway in rat dentate gyrus: synaptic currents evoked in presence and absence of seizure-induced growth. J Neurophysiol 81:1645-1660.

Patrylo PR, Dudek FE (1998) Physiological unmasking of new glutamatergic pathways in the dentate gyrus of hippocampal slices from kainate-induced epileptic rats. J Neurophysiol 79:418-429.

Perez Y, Morin F, Beaulieu C, Lacaille JC (1996) Axonal sprouting of CA1 pyramidal cells in hyperexcitable hippocampal slices of kainatetreated rats. Eur J Neurosci 8:736-748.

Peters A, Palay S, Webster H (1991) The fine structure of the nervous system: neurons and their supporting cells. New York: Oxford.

Pickel VM, Chan J, Sesack SR (1993) Cellular substrates for interactions between dynorphin terminals and dopamine dendrites in rat ventral tegmental area and substantia nigra. Brain Res 602:275-289.

Przewlocka B, Lason W, Machelska H, van Luijtelaar G, Coenen A, Przewlocki R (1995) Kappa opioid receptor agonists suppress absence seizures in WAG/Rij rats. Neurosci Lett 186:131-134.

Ribak CE, Peterson GM (1991) Intragranular mossy fibers in rats and gerbils form synapses with the somata and proximal dendrites of basket cells in the dentate gyrus. Hippocampus 1:355-364.

Scharfman HE (1995) Electrophysiological evidence that dentate hilar mossy cells are excitatory and innervate both granule cells and interneurons. J Neurophysiol 74:179-194.

Scharfman HE, Schwartzkroin PA (1988) Electrophysiology of morphologically identified mossy cells of the dentate hilus recorded in guinea pig hippocampal slices. J Neurosci 8:3812-3821.
Segal M (1979) A potent inhibitory monosynaptic hypothalamohippocampal connection. Brain Res 162:137-141.

Simmons ML, Chavkin C (1996) $\kappa$-Opioid receptor activation of a dendrotoxin-sensitive potassium channel mediates presynaptic inhibition of mossy fiber neurotransmitter release. Mol Pharmacol 50:80-85.

Simmons ML, Terman GW, Drake CT, Chavkin C (1994) Inhibition of glutamate release by presynaptic kappa ${ }_{1}$ opioid receptors in the guinea pig dentate gyrus. J Neurophysiol 72:1697-1705.

Simmons ML, Terman GW, Gibbs SM, Chavkin C (1995) L-type calcium channels mediate dynorphin neuropeptide release from dendrites but not axons of hippocampal granule cells. Neuron 14:1265-1272.

Simmons ML, Terman GW, Chavkin C (1997) Spontaneous excitatory currents and kappa-opioid receptor inhibition in dentate gyrus are increased in the rat pilocarpine model of temporal lobe epilepsy. J Neurophysiol 78:1860-1868.

Sloviter RS (1999) Status epilepticus-induced neuronal injury and network reorganization. Epilepsia 40[Suppl 1]:S34-39, S40-31.

Stanfield BB (1989) Excessive intra- and supragranular mossy fibers in the dentate gyrus of tottering $(\mathrm{tg} / \mathrm{tg})$ mice. Brain Res 480:294-299.

Sutula T, Xiao-Xian H, Cavazos J, Scott G (1988) Synaptic reorganization in the hippocampus induced by abnormal functional activity. Science 239:1147-1150.

Sutula T, Zhang P, Lynch M, Sayin U, Golarai G, Rod R (1998) Synaptic and axonal remodeling of mossy fibers in the hilus and supragranular region of the dentate gyrus in kainate-treated rats. J Comp Neurol 390:578-594.

Terman GW, Wagner JJ, Chavkin C (1994) Kappa opioids inhibit induction of long-term potentiation in the dentate gyrus of the guinea pig hippocampus. J Neurosci 14:4740-4747.

Tortella FC, Robles L, Holaday JW (1986) U50,488, a highly selective kappa opioid: anticonvulsant profile in rats. J Pharmacol Exp Ther 237:49-53.

Wagner JJ, Evans CJ, Chavkin C (1991) Focal stimulation of mossy fibers releases endogenous dynorphins that bind $\mathrm{k}_{1}$-opioid receptors in guinea pig hippocampus. J Neurochem 57:333-343.

Wagner JJ, Terman GW, Chavkin C (1993) Endogenous dynorphins inhibit excitatory neurotransmission and block LTP induction in the hippocampus. Nature 363:451-454.

Weisskopf MG, Zalutsky RA, Nicoll RA (1993) The opioid peptide dynorphin mediates heterosynaptic depression of hippocampal mossy fibre synapses and modulates long-term potentiation. Nature 362:423-427.

Wenzel HJ, Buckmaster PS, Anderson NL, Wenzel ME, Schwartzkroin PA (1997) Ultrastructural localization of neurotransmitter immunoreactivity in mossy cell axons and their synaptic targets in the rat dentate gyrus. Hippocampus 7:559-570.

Williams SH, Johnston D (1996) Actions of endogenous opioids on NMDA receptor-independent long-term potentiation in area CA3 of the hippocampus. J Neurosci 16:3652-3660.

Williamson A, Patrylo PR, Spencer DD (1999) Decrease in inhibition in dentate granule cells from patients with medial temporal lobe epilepsy. Ann Neurol 45:92-99.

Wolfer DP, Lipp HP (1995) Evidence for physiological growth of hippocampal mossy fiber collaterals in the guinea pig during puberty and adulthood. Hippocampus 5:329-340.

Wong RK, Traub RD, Miles R (1986) Cellular basis of neuronal synchrony in epilepsy. Adv Neurol 44:583-592.

Zhang N, Houser CR (1999) Ultrastructural localization of dynorphin in the dentate gyrus in human temporal lobe epilepsy: a study of reorganized mossy fiber synapses. J Comp Neurol 405:472-490. 